\title{
Growth temperature affects accumulation of exogenous fatty acids and fatty acid composition in Schizosaccharomyces pombe
}

\author{
Virginia M. McDonough ${ }^{1, *}$ and Therese M. Roth ${ }^{1,2}$ \\ ${ }^{1}$ Department of Biology, Hope College, Holland, MI 49422-9000; ${ }^{2}$ Current address: Department of Cell and \\ Developmental Biology, University of Michigan Medical School, Ann Arbor, MI; *Author for correspondence \\ (e-mail: mcdonough@hope.edu; phone: 616 395-7715; fax: 616 395-7125)
}

Received 22 December 2003; Accepted in revised form 3 June 2004

Key words: Fatty acid, Schizosaccharomyces pombe

\begin{abstract}
The incorporation of exogenously supplied fatty acids, palmitic acid, palmitoleic acid, oleic acid and linoleic acid, was examined in the yeast Schizosaccharomyces pombe at two growth temperatures, $20^{\circ} \mathrm{C}$ and $30^{\circ} \mathrm{C}$. Fatty acids supplied to $S$. pombe in the growth medium were found to be preferentially incorporated into the cells, becoming a dominant species. The relative increase in exogenous fatty acids in cells came at the expense of endogenous oleic acid as a proportion of total fatty acids. Lowering the temperature at which the yeast were grown resulted in decreased levels of incorporation of the fatty acids palmitic acid, palmitoleic acid and linoleic acid compared to cells supplemented at $30^{\circ} \mathrm{C}$. In addition, the relative amount of the endogenously produced unsaturated fatty acid oleic acid, while greatly reduced compared to unsupplemented cells, was increased in cells supplemented with fatty acids at $20{ }^{\circ} \mathrm{C}$ compared to supplemented cells at $30{ }^{\circ} \mathrm{C}$. The differential production of oleic acid in $S$. pombe cells indicates that regulation of unsaturated fatty acid levels, possibly by control of the stearoyl-CoA desaturase, is an important control point in membrane composition in response to temperature and diet in this species.
\end{abstract}

Abbreviations: $\mathrm{x}: \mathrm{y} \Delta \mathrm{n}$ - fatty acids containing x carbon atoms and y cis double bonds located at position $\mathrm{n}$ from the carboxyl end; 16:0 - palmitic acid; 16: $\Delta 9$ - palmitoleic acid; 18:0 - stearic acid; 18:1 $\Delta 9$ - oleic acid; 18:2 $\Delta 9,12$ - linoleic acid; YEt - yeast medium composed of $0.5 \%$ yeast nitrogen base, $3 \%$ dextrose, supplemented with appropriate amino acids, uracil, adenine, and 1\% tergitol NP-40

\section{Introduction}

All microorganisms respond to change in their environment. One common mechanism is the alteration of lipid composition in order to optimize membrane structure and function. For example, in response to lower growth temperatures, many eukaryotic microorganisms respond by changing the relative proportion of unsaturated fatty acids in the membrane and/or altering fatty acid chain length (Fukushima et al. 1976; Okuyama et al. 1979; Suutari et al. 1990; Suutari and Laakso 1994).
In some yeast species, decreasing growth temperature results in an increase in the unsaturated fatty acid content (Arthur and Watson 1976; Suutari et al. 1990; Suutari et al. 1997). In the well-studied Saccharomyces cerevisiae, growth at lower temperatures resulted in higher levels of unsaturated fatty acids and shorter chain length (Okuyama, Saito et al. 1979; Los and Murata 1998). The ability of an organism to manipulate the fatty acid composition of its membranes is dependent on many aspects of metabolism including synthesis, degradation, and incorporation of exogenous fatty acids. 
Addition of fatty acids to the growth medium of the yeast Sacc. cerevisiae results in a modification of the fatty acid composition. The cellular mechanism that accomplishes the fatty acid profile modification in response to exogenous fatty acids includes a decrease in the expression of acetyl CoA synthase and fatty acid synthase (Chirala 1992). In addition, supplementing Sacc. cerevisiae's growth medium with unsaturated fatty acids containing a C9-C10 double bond results in decreased expression of the stearoyl CoA desaturase and in the de novo synthesis of endogenous unsaturated fatty acids (Stukey et al. 1989; Stukey et al. 1990; McDonough et al. 1992). However, feeding the saturated fatty acid palmitic acid (16:0) to Sacc. cerevisiae results in a modest increase in the desaturase expression (Bossie and Martin 1989).

The organism's use of exogenous fatty acids requires a balance between energy saved in fatty acid production and membrane function at the growth temperature. One might hypothesize that different growth temperatures would influence fatty acid uptake and usage, and concomitantly alter regulation of fatty acid biosynthetic enzymes based on the needs of the cell for optimal membrane function at the different temperatures. However, the effect of growth temperature on exogenous fatty acid accumulation and/or subsequent regulatory actions have not been addressed.

In the model organism Schizosaccharomyces pombe, fatty acid composition has been examined by various investigators (Koukou et al. 1990; Jeffery et al. 1997; Malfeito-Ferreira et al. 1997). However, fatty acid composition in temperature adaptation or after supplementation with fatty acids has not been extensively studied. We describe here a series of experiments in S. pombe in an effort to understand how growth temperature affects the membrane profile and accumulation of exogenous fatty acids. In addition, we examined the cellular manipulation of fatty acid production in response to the simultaneous changes in temperature and availability of fatty acid supplements.

\section{Materials and methods}

\section{Reagents}

Amino acids, boron trifluoride, fatty acids, fatty acid methyl esters, fatty acid methyl esters standard AOCS
\# 5, and tergitol NP-40 were all purchased from Sigma. All standard media supplies were from Difco. Other chemicals were reagent grade and purchased from Fisher.

\section{Strain and media}

S. pombe strain $975 \mathrm{~h}+$ (supplied by Dr. Susan Henry) was used in these studies. S. pombe was grown in $\mathrm{YE}_{\mathrm{t}}$ medium, which is $0.5 \%$ yeast nitrogen base, $3 \%$ dextrose, $1 \%$ tergitol NP-40, supplemented with complete amino acid stock, uracil, and adenine (Alfa et al. 1993). Fatty acids were stored as stock solutions of $100 \mathrm{mM}$ in ethanol and supplemented to $\mathrm{YE}_{\mathrm{t}}$ medium as noted (ethanol concentration was maintained at $1 \%)$. $\mathrm{YE}_{\mathrm{t}}$ media without fatty acids contained $1 \%$ ethanol. Cell densities were determined by counting with a hemacytometer.

\section{Fatty Acid Analyses}

To analyze total fatty acids, including both free and esterified, cells were cultured at noted temperature in $200 \mathrm{ml} \mathrm{YNBt}$ overnight to a maximum density of 1-2 $\times 10^{7}$ cells $/ \mathrm{ml}$. Fatty acids in ethanol, or ethanol alone, was added to cultures and incubation continued for four additional hours. Cells were harvested by centrifugation in a Beckman J2-MI centrifuge at 4000 $\times$ g at $4{ }^{\circ} \mathrm{C}$. The cells were washed with sterile water to remove residual media. Lipids were saponified and converted to methyl esters by a modified Bligh-Dyer method (Bligh and Dyer 1959). Samples of fatty acid methyl esters were analyzed by gas chromatography on a Hewlett-Packard model 6890 gas chromatograph using a $30 \mathrm{~m}$ HP-5 column. Instrument conditions were as follows: injection port temperature $220^{\circ} \mathrm{C}$, detector temperature $300{ }^{\circ} \mathrm{C}$, initial oven temperature at $140{ }^{\circ} \mathrm{C}$. After a 1 minute hold at $140{ }^{\circ} \mathrm{C}$, the oven temperature was increased at $4{ }^{\circ} \mathrm{C} /$ minute up to a temperature of $260{ }^{\circ} \mathrm{C}$ followed by a $10{ }^{\circ} \mathrm{C} /$ minute increase to a final temperature of $300{ }^{\circ} \mathrm{C}$ held for 5 minutes. Identification of cellular fatty acid species was by comparison of retention times to those of standard compounds. A minimum of five replicates, from at least two experiments, was used to determine mean and standard deviation values. Statistical analysis by t-test was performed using KaleidaGraph software (Synergy). 


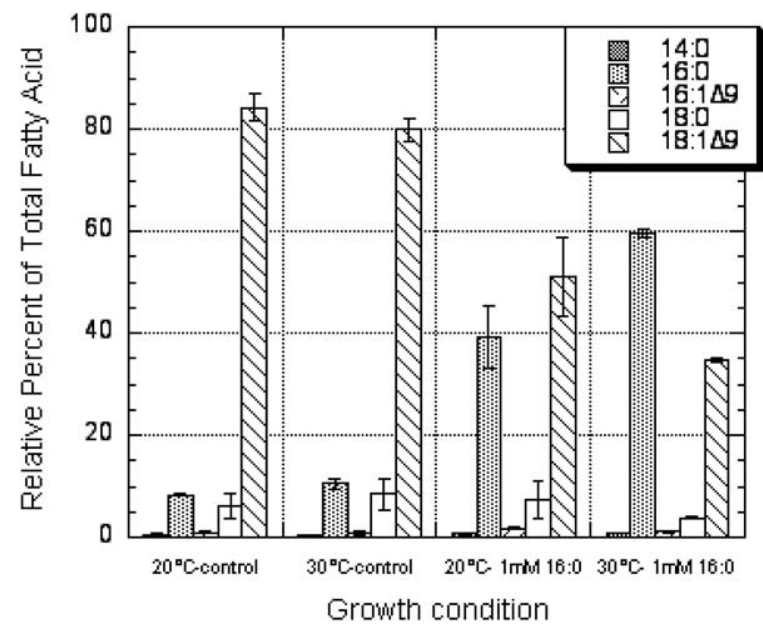

Figure 1. Fatty acid composition of $S$. pombe supplemented with 1 $\mathrm{mM} \mathrm{16:0}$ at $20^{\circ} \mathrm{C}$ and $30{ }^{\circ} \mathrm{C}$; Cells were cultured at noted temperature in $\mathrm{YE}_{\mathrm{t}}$ overnight either with or without $1 \mathrm{mM} \mathrm{16:0} \mathrm{to} \mathrm{a}$ maximum density of $3 \times 10^{6}$ cells $/ \mathrm{ml}$. Cells were harvested, lipids saponified and converted to methyl esters by a modified Bligh-Dyer method as described in materials and methods. Fatty acid methyl esters were analyzed by gas chromatography, and identified by comparison to authentic standards. A minimum of five replicates, from at least two experiments, was used to determine mean and standard deviation values. Control represents no supplemented fatty acid.

\section{Results and discussion}

In unsupplemented cultures of $S$. pombe, we found oleic acid $(18: 1 \Delta 9)$ to be by far the dominant fatty acid species in both temperature conditions (Figure 1, 'control'), accounting for $80-85 \%$ of the total fatty acids. There was a small but statistically significant $(\mathrm{p}<0.01)$ increase in the relative proportion of 18:1 $\Delta 9$ at the cells cultured at the lower temperature $\left(84.2 \%\right.$ at $20{ }^{\circ} \mathrm{C}$ vs. $79.9 \%$ at $\left.30{ }^{\circ} \mathrm{C}\right)$. The unsaturated fatty acid palmitoleic acid (16:1 $\Delta 9)$ accounted for about $1 \%$ of total fatty acids under either growth condition. The balance was mostly 16 or 18 carbon saturated fatty acids. The relative increase in $18: 1 \Delta 9$ seen at $20^{\circ} \mathrm{C}$ was made up mainly at the expense of these two saturates.

Supplying the saturated fatty acid palmitic acid (16:0) to cultures resulted in a dramatic increase in the relative proportion of that fatty acid (Figure 1). At either temperature, we observed an approximate five fold increase in 16:0 proportion in supplemented cells compared to unsupplemented.

Growth temperature did affect the relative accumulation of 16:0. The relative content of the exogenously

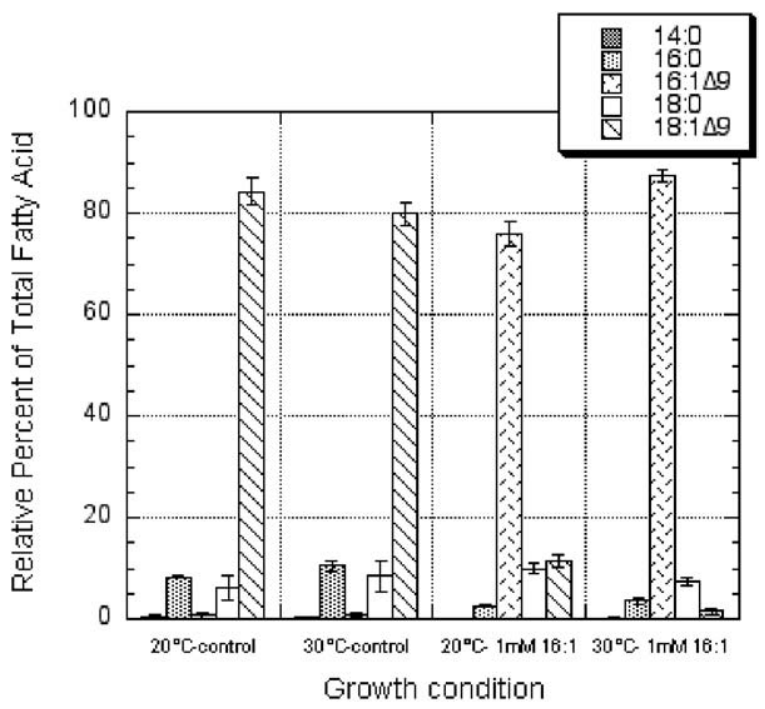

Figure 2. Fatty acid composition of $S$. pombe supplemented with 1 $\mathrm{mM} 16: 1 \Delta 9$ at $20^{\circ} \mathrm{C}$ and $30{ }^{\circ} \mathrm{C}$; Cells were cultured at noted tem-

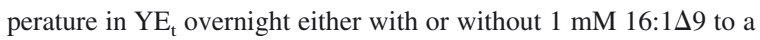
maximum density of $3 \times 10^{6}$ cells $/ \mathrm{ml}$. Lipids were prepared and analyzed as described in Figure 1.

supplied 16:0 was increased by approximately one third (from $39 \%$ to $60 \%$ ) when culture temperature was increased from $20{ }^{\circ} \mathrm{C}$ to $30{ }^{\circ} \mathrm{C}$ (Figure 1). We also observed that the relative proportion of endogenously produced $18: 1 \Delta 9$ was altered in response to 16:0 supplementation. Cells supplied 16:0 contained about $50 \%$ more $18: 1 \Delta 9$ when cultured at $20^{\circ} \mathrm{C}$ as compared to $30{ }^{\circ} \mathrm{C}(50.9 \%$ vs. $34.6 \%)$. However, the relative proportion of $18: 1 \Delta 9$ observed in either culture was greatly reduced compared to growth under unsupplemented conditions.

The increase in 16:0 proportion in the cells was not accompanied by an increase in $16: 1 \Delta 9$. This was somewhat surprising, as in many species 16:0, in addition to stearic acid (18:0), can serve as a substrate for the fatty acid desaturase (for some examples see (Jeffcoat et al. 1977; Prasad and Joshi 1979; Stukey et al. 1989)). Interesting work by Shanklin and colleagues have shown that modification of specific residues in the plant acyl carrier protein desaturase can alter the substrate preference (Cahoon et al. 1997; Cahoon et al. 1998; Whittle and Shanklin 2001). Comparing the sequence of the $S$. pombe desaturase protein to other CoA-dependent desaturases may help identify key residues that provide substrate specificity. 


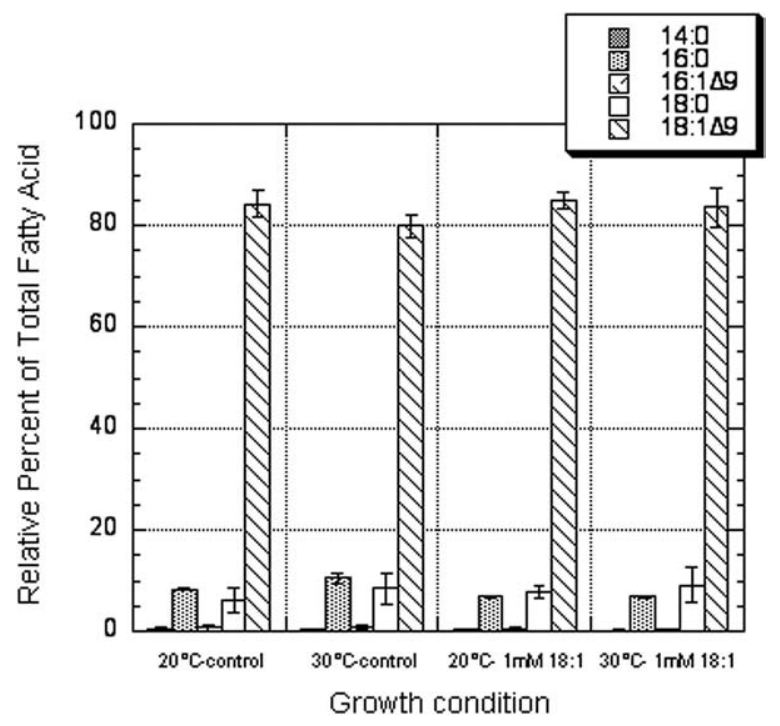

Figure 3. Fatty acid composition of $S$. pombe supplemented with 1 $\mathrm{mM} \mathrm{18:1 \Delta 9}$ at $20^{\circ} \mathrm{C}$ and $30{ }^{\circ} \mathrm{C}$; Cells were cultured at noted tem-

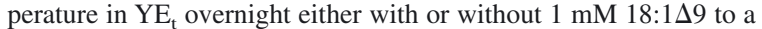
maximum density of $3 \times 10^{6}$ cells $/ \mathrm{ml}$. Lipids were prepared and analyzed as described in Figure 1.

When cells were fed the unsaturated fatty acid $16: 1 \Delta 9$, they readily used it as a replacement for the principal fatty acid $18: 1 \Delta 9$ (Figure 2 ). At $30^{\circ} \mathrm{C}$, the relative proportion of cellular 16:1 $\Delta 9$ increased from the unsupplemented level of $0.9 \%$ to $87.4 \%$ in supplemented medium, while at $20{ }^{\circ} \mathrm{C}$, the relative proportion of $16: 1$ increased from $1 \%$ to $76 \%$ of total fatty acids (Figure 2). In both cases, the increase in $16: 1 \Delta 9$ was accompanied by a concomitant decrease in relative proportion of endogenous 18:1 $\Delta 9$. At $20{ }^{\circ} \mathrm{C}$, the endogenously produced $18: 1 \Delta 9$ accounted for $11.5 \%$ of the total fatty acids, while at $30{ }^{\circ} \mathrm{C}$, $18: 1 \Delta 9$ represented only about $1.5 \%$ of total fatty acids.

An exogenous source of $18: 1 \Delta 9$ resulted in no large scale change to the cells' fatty acid profiles at either growth temperature (Figure 3 ). We assume that the exogenous 18:1 $\Delta 9$ has replaced endogenous, but are unable to verify this assumption. One change noted is that the small, relative proportion of $16: 1 \Delta 9$ observed in unsupplemented cells decreases even more in the $18: 1 \Delta 9$ supplemented cultures. In $20^{\circ} \mathrm{C}$ cultured cells, we observed that the relative concentration of endogenous $16: 1 \Delta 9$ decreased from $1 \%$ to $0.5 \%$ (unsupplemented to $18: 1 \Delta 9$ supplemented), while in $30{ }^{\circ} \mathrm{C}$ cultured cells, the relative concentration of $16: 1 \Delta 9$ decreased from $0.9 \%$ to $0.3 \%$.

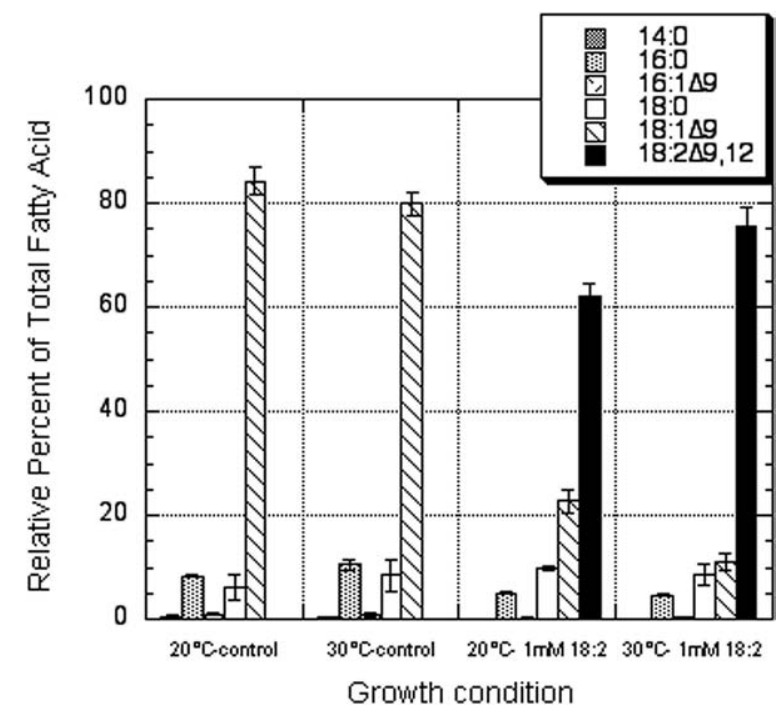

Figure 4. Fatty acid composition of $S$. pombe supplemented with 1

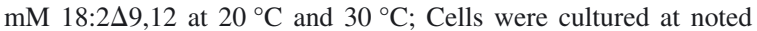
temperature in $\mathrm{YE}_{\mathrm{t}}$ overnight either with or without $1 \mathrm{mM}$ $18: 2 \Delta 9,12$ to a maximum density of $3 \times 10^{6}$ cells $/ \mathrm{ml}$. Lipids were prepared and analyzed as described in Figure 1.

The cells readily accumulated linoleic acid $(18: 2 \Delta 9,12)$ from their environment, making it the predominant fatty acid species in the cell, in spite of the fact that that it is not a normal component of the fatty acid profile. However, the degree of accumulation was dictated by culture temperature (Figure 4 ). An exogenous source of 18:2 $\Delta 9,12$ resulted in cells containing $62 \% \quad 18: 2 \Delta 9,12$ at $20^{\circ} \mathrm{C}$ and $75 \%$ $18: 2 \Delta 9,12$ at $30^{\circ} \mathrm{C}$. Culture temperature not only affected the relative proportion of $18: 2 \Delta 9,12$, it also affected the relative proportion of 18:1 $\Delta 9$. The increase in 18:2 $\Delta 9,12$ was balanced by a decrease in endogenous 18:1 $\Delta 9$. In cells cultured at $20^{\circ} \mathrm{C}$ with $18: 2, \Delta 9,12$ supplement, we observed that $18: 1 \Delta 9$ represented $22.7 \%$ of the total fatty acids, while cells cultured at $30^{\circ} \mathrm{C}$ with $18: 2, \Delta 9,12$ contained only $11.2 \% 18: 1 \Delta 9$.

\section{Conclusions}

Addition of fatty acids to the growth medium of $S$. pombe resulted in dramatic alteration in fatty acid profiles. The supplemented fatty acid became a predominant species of the fatty acid profile. We noted with interest that the relative proportion of endogenous $18: 1 \Delta 9$ is the main focus of response. This re- 
Table 1. Comparison of growth temperature and fatty acid supplement on the fatty acid profile of S. pombe. FA- fatty acid, UFA- unsaturated fatty acid

\begin{tabular}{|c|c|c|c|c|c|c|}
\hline Growth condition & $\begin{array}{l}20^{\circ} \mathrm{C} \text { supple- } \\
\text { mented FA as } \% \\
\text { of total profile }\end{array}$ & $\begin{array}{l}30{ }^{\circ} \mathrm{C} \text { supple- } \\
\text { mented FA as } \% \\
\text { of total profile }\end{array}$ & $20^{\circ} \mathrm{C}$ Total UFA & $30^{\circ} \mathrm{C}$ Total UFA & $\begin{array}{l}20^{\circ} \mathrm{C} \text { Native } \\
18: 1 \Delta 9\end{array}$ & $\begin{array}{l}30{ }^{\circ} \mathrm{C} \text { Native } \\
18: 1 \Delta 9\end{array}$ \\
\hline No Supplement & - & - & $85.2 \%$ & $80.8 \%$ & $84.2 \%$ & $79.9 \%$ \\
\hline $1 \mathrm{mM} \mathrm{16:0}$ & $39.2 \%$ & $60.0 \%$ & 52.5 & 35.6 & 50.9 & 34.6 \\
\hline $1 \mathrm{mM} \mathrm{16:1 \Delta 9}$ & 75.8 & 87.4 & 87.4 & 88.9 & 11.5 & 1.5 \\
\hline $1 \mathrm{mM} \mathrm{18:1 \Delta 9}$ & 84.9 & 83.6 & 85.3 & 83.9 & Cannot determine & Cannot determine \\
\hline $1 \mathrm{mM} 18: 2 \Delta 9,12$ & 62.0 & 75.5 & 84.8 & 86.8 & 22.7 & 11.2 \\
\hline
\end{tabular}

sponse may come from regulation of expression and activity of the stearoyl-CoA desaturase, although preferential turnover of $18: 1 \Delta 9$ is also a formal possibility.

Decreasing the growth temperature of $S$. pombe from $30^{\circ} \mathrm{C}$ to $20^{\circ} \mathrm{C}$ resulted in very small change in the fatty acid profile of unsupplemented cells, with a small but significant increase in relative proportion of $18: 1 \Delta 9$ observed at the lower growth temperature. However, a few clear differences in response to temperature in supplemented cells present themselves. First, we observed supplements of 16:0, 16:1 19 , or $18: 2 \Delta 9,12$ resulted in less accumulation at the $20^{\circ} \mathrm{C}$ culture condition than at $30{ }^{\circ} \mathrm{C}$ (table 1). Second, we observed increased relative amounts of native 18:1 19 in fatty acid supplemented cells cultured at $20{ }^{\circ} \mathrm{C}$ then those cultured at the higher growth temperature. A strong contender for responsibility for this differential is again regulation of the stearoyl-CoA desaturase.

We note with interest that the relative concentration of unsaturated fatty acids is kept fairly constant, except when fed a saturated fatty acid (Table 1). However, this total amount of unsaturated fatty acid represents a balance of accumulation of exogenous fatty acid and endogenous production of 18:1 $\Delta 9$ (Table 1). It appears that the response to fatty acid supplements mainly revolves around modulation of endogenous 18:1 $\Delta 9$.

Our work shows the plasticity of $S$. pombe requirements for specific fatty acid species, and the careful response of the cells to supplies of exogenous fatty acids and temperature. Clearly, an important control point for $S$. pombe is the regulation of the relative proportion of $18: 1 \Delta 9$ present in the membranes. This most likely results from a modification of expression and/or activity of the stearoyl-CoA desaturase. We are currently starting to address the molecular mechanisms involved in modifying lipid composition in this model organism.

\section{Acknowledgements:}

This work was supported by National Science Foundation Research Experience for Undergraduates Grant DB1-9820571.

We thank Dr. Susan Henry (Cornell University) for supplying Schizosaccharomyces pombe strain $975 \mathrm{~h}+$; the Hope College Department of Chemistry for the use of the gas chromatograph, and Drs. J. Stukey, E. Sanford and W. Mungall for their technical assistance in its operation.

\section{References}

Alfa C., Fantes P., Hyams J., McLeod M. and Warbrick E. , (eds) 1993. Experiments with Fission Yeast. Cold Spring Harbor Laboratory Press, Plainview, New York, USA.

Arthur H. and Watson K. 1976. Thermal adaptation in yeast: growth temperatures, membrane lipid, and cytochrome composition of psychrophilic, mesophilic, and thermophilic yeasts. J. Bacteriol. 128: 56-69.

Bligh E.G. and Dyer W.J. 1959. A rapid method of total lipid extraction and purification. Can. J. Biochem. Physiol. 37: 911-917.

Bossie M.A. and Martin C.E. 1989. Nutritional regulation of yeast $\Delta-9$ fatty acid desaturase activity. J. Bacteriol. 171: 6409-6413.

Cahoon E.B., Lindqvist Y., Schneider G. and Shanklin J. 1997. Redesign of soluble fatty acid desaturases from plants for altered substrate specificity and double bond position. Proc. Natl. Acad. Sci. USA 94(10): 4872-7.

Cahoon E.B., Shah S., Shanklin J. and Browse J. 1998. A determinant of substrate specificity predicted from the acyl-acyl carrier protein desaturase of developing cat's claw seed. Plant Physiol. 117(2): 593-8.

Chirala S.S. 1992. Coordinated regulation and inositol-mediated and fatty acid-mediated repression of fatty acid synthase genes in Saccharomyces cerevisiae. Proc. Natl. Acad. Sci. USA 89: 10232-6.

Fukushima H., Martin C.E., Iida H., Kitajima Y. and Thompson G.A. Jr. 1976. Changes in membrane lipid composition during temperature adaptation by a thermotolerant strain of Tetrahymena pyriformis. Biochim. Biophys. Acta 431(1): 165-79. 
Jeffcoat R., Brawn P.R., Safford R. and James A.T. 1977. Properties of rat liver microsomal stearoyl-CoA desaturase. Biochem. J. 161: 431-437.

Jeffery J., Kock J.L., Botha A., Coetzee D.J. and Botes P.J. 1997. The value of lipid composition in the taxonomy of the Schizosaccharomycetales. Antonie Van Leeuwenhoek 72(4): 327-35.

Koukou A.I., Tsoukatos D. and Drainas C. 1990. Effect of ethanol on the phospholipid and fatty acid content of Schizosaccharomyces pombe membranes. J. Gen. Microbiol. 136: 1271-7.

Los D.A. and Murata N. 1998. Structure and expression of fatty acid desaturases. Biochimi. Biophysi. Acta. 1394: 3-15.

Malfeito-Ferreira M., Tareco M. and Loureiro V. 1997. Fatty acid profiling: a feasible typing system to trace yeast contamination in wine bottling plants. Int. J. Food Microbiol. 38: 143-55.

McDonough V.M., Stukey J.E. and Martin C.E. 1992. Specificity of unsaturated fatty acid- regulated expression of the Saccharomyces cerevisiae OLE1 Gene. J. Biol. Chem. 267: 5931-5936.

Okuyama H., Saito M., Joshi V.C., Gunsberg S. and Wakil S.J. 1979. Regulation by temperature of the chain length of fatty acids in yeast. J. Biol. Chem. 254(24): 12281-4.

Prasad M.R. and Joshi V.C. 1979. Purification and properties of hen liver microsomal terminal enzyme involved in stearoyl coen- zyme A desaturation and its quantitation in neonatal chicks. J. Biol. Chem. 254(14): 6362-6369.

Stukey J.E., McDonough V.M. and Martin C.E. 1989. Isolation and characterization of $O L E 1$, a gene affecting fatty acid desaturation from Saccharomyces cerevisiae. J. Biol. Chem. 264: 16537-16544.

Stukey J.E., McDonough V.M. and Martin C.E. 1990. The OLE1 gene of Saccharomyces cerevisiae encodes the $\Delta 9$ fatty acid desaturase and can be functionally replaced by the rat stearoyl-CoA desaturase gene. J. Biol. Chem. 265: 20144-20149.

Suutari M. and Laakso S. 1994. Microbial fatty acids and thermal adaptation. Crit Rev Microbiol. 20(4): 285-328.

Suutari M., Liukkonen K. and Laakso S. 1990. Temperature adaptation in yeasts: the role of fatty acids. J. Gen. Microbiol. 136: 1469-74.

Suutari M., Rintamaki A. and Laakso S. 1997. Membrane phospholipids in temperature adaptation of Candida utilis: alterations in fatty acid chain length and unsaturation. J. Lipid Res. 38(4): $790-4$.

Whittle E. and Shanklin J. 2001. Engineering delta 9-16:0-acyl carrier protein (ACP) desaturase specificity based on combinatorial saturation mutagenesis and logical redesign of the castor delta 9-18:0-ACP desaturase. J. Biol. Chem. 276(24): 21500-5. 